\title{
Controlling the Emitter Orientation in Solution-processed Films through Introduction of Mesogenic Groups within a Multi-resonance Thermally Activated Delayed Fluorescence Emitter
}

Dongyang Chen, ${ }^{a}$ Francisco Tenopala-Carmona,${ }^{b}$ Julius A. Knöller, ${ }^{c}$ Andreas Mischok, ${ }^{b}$ David Hall,,${ }^{a, d}$ Subeesh Madayanad Suresh, ${ }^{a}$ Tomas Matulaitis, ${ }^{a}$ Yoann Olivier, ${ }^{e}$ Pierre Nacke, ${ }^{f}$ Frank Gießelmann, ${ }^{f}$ Sabine Laschat, ${ }^{c *}$ Malte C. Gather, ${ }^{b *}$ Eli Zysman-Colman ${ }^{a *}$

${ }^{a}$ Organic Semiconductor Centre, EaStCHEM School of Chemistry, University of St Andrews, St Andrews, Fife, UK, KY16 9ST, Fax: +44-1334 463808; Tel: +44-1334 463826; E-mail: eli.zysmancolman@st-andrews.ac.uk;

${ }^{b}$ Humboldt Centre for Nano- and Bio-Photonics, Department of Chemistry, University of Cologne, Greinstr. 4 6, 50939 Köln, Germany; Email: malte.gather@uni-koeln.de

${ }^{c}$ Institut für Organische Chemie, Universität Stuttgart, Pfaffenwaldring 55, 70569 Stuttgart, Germany Tel: +49 711/68564565; Email: sabine.laschat@oc.uni-stuttgart.de;

${ }^{d}$ Laboratory for Chemistry of Novel Materials, University of Mons, Mons, Belgium

${ }^{e}$ Laboratory for Computational Modeling of Functional Materials, Namur Institute of Structured Matter, Université de Namur, Rue de Bruxelles, 61, 5000 Namur, Belgium.

${ }^{f}$ Institut für Physikalische Chemie, Universität Stuttgart, Pfaffenwaldring 55, 70569 Stuttgart, Germany; Tel.+49 (0)711/685-64460; Email Email: f.giesselmann@ipc.uni-stuttgart.de

\begin{abstract}
The use of thermally activated delayed fluorescence emitters and emitters that show preferential horizontal orientation of their transition dipole are two emerging strategies to enhance the efficiency of organic lightemitting diodes. We present the first example of a liquid crystalline multi-resonance thermally activated delayed fluorescent emitter, DiKTaLC. The neat film of DiKTaLC shows a photoluminescence quantum yield of $41 \%$, a singlet-triplet energy gap, $\Delta \mathrm{E}_{\mathrm{ST}}$, of $0.20 \mathrm{eV}$, and a delayed lifetime, $\tau_{\mathrm{d}}$, of $70.2 \mu \mathrm{s}$. The compound possesses a nematic discotic liquid crystalline phase between $80{ }^{\circ} \mathrm{C}$ and $110{ }^{\circ} \mathrm{C}$. More importantly, the transition dipole moment of the spin-coated film shows preferential horizontal orientation, with an anisotropy factor, $a$, of 0.26 . We thus demonstrate for the first time how self-assembly of a liquid crystalline TADF emitter can lead to the so-far elusive control of the orientation of the transition dipole in
\end{abstract}


solution-processed films, which will be of relevance for high-performance solution-processed organic lightemitting diodes.

\section{Introduction}

Organic light-emitting diodes (OLEDs) have attracted tremendous interest as a technology for use in displays and solid-state lighting and have already been commercialized in smartphones, television screens and automotive lighting. ${ }^{1}$ OLEDs can be categorized into vacuum-deposited OLEDs (VD-OLEDs) and solution-processed OLEDs (SP-OLEDs), depending on the technique used for their fabrication. ${ }^{2}$ For VDOLEDs, small-molecule, low-weight materials are sublimed into the vapor phase via heating in a highvacuum environment (pressure $<10^{-6}$ Torr) to afford multilayer structures of very high purity. ${ }^{2}$ With appropriate heating and choice of materials, the vacuum-deposited films can exhibit high densities, high thermal stability, and the emitter molecules can show a high degree of horizontal molecular orientation, ${ }^{2-5}$ which are critical for the device to be both stable and show a high maximum external quantum efficiency $\left(\mathrm{EQE}_{\max }\right)$. These advantages make vacuum-deposition the preferred technique for OLEDs fabrication, and to date, commercial OLEDs are mainly produced by this method. However, the fabrication process is both energy-intensive and material-wasteful, and a complex operation process is required to control for doping concentration and film thickness, which contributes to the relatively high fabrication cost associated with VD-OLEDs. ${ }^{6}$ By contrast, SP-OLEDs offer a number of potential advantages, such as low-cost manufacturing, high processing efficiency, a relatively small amount of wasted material, and a wider choice of materials, from small molecules ${ }^{7,8}$ to polymers ${ }^{9}$ and dendrimers. ${ }^{6,10}$ However, the poor film quality and morphology fabricated by solution-processed methods lead to inferior device lifetime and severe efficiency roll-off of SP-OLEDs, which has, in part, retarded the commercialization of SP-OLEDs. ${ }^{6}$

The efficiency of the OLEDs is based partly on the capacity of the emitter material to harvest both the emissive singlet and triplet excitons generated within the emission layer to produce light, which is reflected 
in the internal quantum efficiency (IQE). There are two classes of materials that can attain up to $100 \%$ IQE: phosphorescent emitters ${ }^{11}$ and thermally activated delayed fluorescence (TADF) emitters. ${ }^{1,12,13}$ Organic TADF emitters harvest all excitons as a result of the small energy gap between singlet and triplet states $\left(\Delta \mathrm{E}_{\mathrm{ST}}\right)$, which permits the non-emissive triplets to be efficiently up-converted into emissive singlets by a reverse intersystem crossing (RISC) process. ${ }^{14,15}$ The EQE of the OLED depends not only on the IQE, but also on the light out-coupling efficiency $\left(\eta_{\text {out }}\right)$, as shown in equation $(1):^{16}$

$E Q E=I Q E \times \eta_{\text {out }}$

The $\eta_{\text {out }}$ is dependent on the orientation of the transition dipole moment (TDM) of the emitter molecules. For the case where the TDMs are randomly oriented within the emissive layer, the $\eta_{\text {out }}$ typically has a value of $20-30 \%$, thus indicating that only a small amount of the light produced within the emissive layer actually exits the device for productive use. ${ }^{17,18}$ A general method to improve $\eta_{\text {out }}$ is to horizontally orient the TDM of the emitters, as the emission of light proceeds predominantly in a direction perpendicular to the TDM. ${ }^{19}$ It is possible to infer the average orientation of the TDMs within a film, ${ }^{4}$ which is done typically by either angle-resolved photoluminescence (ARPL) or variable-angle spectroscopic ellipsometry (VASE) studies. ${ }^{19-21}$ Yokoyama's fundamental work on small molecule orientation in vacuum-deposited films has demonstrated that to minimize the surface energy, the "first" layer of the molecules deposited on the interface adopts a horizontal orientation, but then the molecules can quickly undergo surface diffusion until the orientation is fixed by successively overlaying molecules. ${ }^{2}$ Indeed, the orientation of the TDM in vacuum-deposited films is influenced by not only the intrinsic anisotropy of the emitter molecule, ${ }^{22}$ but also the temperature of the substrate, ${ }^{23}$ and the intermolecular interactions within the emissive layer. ${ }^{24,25}$ There are now a number of examples of VD-OLEDs that contain highly horizontally oriented TADF emitters. ${ }^{4}$ For SP-OLEDs, the TDM in polymer devices were found to show preferential horizontal orientation even before TDM orientation was investigated in VD-OLEDs. ${ }^{26-29}$ However, when using small molecule-based emitters for SP-OLEDs, the absence of the strong molecular anisotropy imposed by polymer chains and the simultaneous condensation and solidification of the material during the spin-coating often lead to isotropic 
TDM orientation in the final film. ${ }^{5,30}$ Moreover, the solvent volatilization leaves voids in the film, which provides sufficient space for the emitters to re-orient to a thermodynamically more stable configuration, often resulting in a net isotropic orientation. ${ }^{30}$ Thus, unlike emitters that can show preferential horizontal orientation in vacuum-deposited films, small molecule emitters in solution-processed films do not usually show any preferred orientation. This is exemplified for the TADF emitter DACT-II, which shows $86 \%$ of horizontal orientation in vacuum-deposited doped films in CBP, but the same molecule is isotropic in solution-processed films. ${ }^{31,32}$ A strategy to obtain highly horizontally oriented TDMs in solution-processed films must exploit intermolecular interactions to drive the assembly of higher order films.

Liquid crystalline (LC) materials can form highly ordered microstructures via intermolecular interaction and give rise to anisotropic properties..$^{33,34}$ The alignment direction of liquid crystalline materials can be controlled by simple thermal treatment, electrical field treatment, and mechanical force treatment. ${ }^{35-37}$ Luminous LC materials have been used as emitters in OLEDs due to their controllable photophysical and thermal properties, and charge carrier mobility. ${ }^{38-40}$ Bock et al. explored the bipolar columnar liquid crystals alkyl esters of perylene 3,4,9,10-tetracarboxylic acid (3a-h) as emitters in OLEDs. These compounds emitted from orange to red in an evaporated single layer OLED, and the device with $\mathbf{3 b}$ exhibited a turn-on voltage of $7 \mathrm{~V}$ and maximum luminance $\left(\operatorname{Lum}_{\max }\right)$ over $100 \mathrm{~cd} \mathrm{~m}^{-2} .{ }^{41,42}$ Murawski et al. further investigated the TDM orientation of the LC emitter perylene-3,4,9,10-tetracarboxylic tetraethyl ester (PTCTE), when doped in different host materials. ${ }^{21}$ The TDM of PTCTE shows preferential horizontal orientation ( $72 \%$ horizontal) as a $2 \mathrm{wt} \%$ doped TCTA:TPBi film but with a low $\Phi_{\mathrm{PL}}$ of $14 \%$; however, the orientation is isotropic in a TCTA:B3PYMPM film $\left(\Phi_{\mathrm{PL}}\right.$ of $\left.13 \%\right){ }^{21}$ As a result, the OLEDs based on PTCTE/TCTA:B3PYMPM exhibited very low $\mathrm{EQE}_{\max }$ below $0.3 \%$ at $\lambda_{\mathrm{EL}}$ of $550 \mathrm{~nm}$, while for device based on PTCTE/TCTA:TPBi showed an improved EQE $E_{\max }$ of $0.8 \%$ at $\lambda_{\mathrm{EL}}$ of $580 \mathrm{~nm} .{ }^{21}$ Mesogenic phosphorescent emitters based on iridium and platinum have also been employed in solution-processed OLEDs, and these devices have the potential to show higher $\mathrm{EQE}_{\max }$ due to the ability of the emitter to 
convert both singlet and triplet excitons to light. ${ }^{43,44}$ Wang et al. reported two chiral, LC cyclometalated platinum complexes, $\boldsymbol{R}$-Pt and $\boldsymbol{S}$-Pt, where mesogenic groups were added to the $\beta$-diketonato ligand to induce liquid crystallinity. ${ }^{45}$ Nematic phases were found for both complexes at $141^{\circ} \mathrm{C}$ by a combination of polarizing optical microscopy (POM), differential scanning calorimetry (DSC), and small-angle X-ray scattering. ${ }^{45}$ An increase of the dissymmetry factor $\left(g_{\mathrm{PL}}\right)$ from 0.004 to 0.06 was observed for the annealed neat film of $\boldsymbol{R}-\mathbf{P t}$, which hints at an ordered orientation after annealing; however, the TDM of $\boldsymbol{R}$-Pt was not investigated in this work. ${ }^{45}$ The $\Phi_{\mathrm{PL}}$ of $\boldsymbol{R}$-Pt and $\boldsymbol{S}$-Pt are 75 and $44 \%$, respectively, in degassed dichloromethane (DCM). The solution-processed OLEDs based on $\boldsymbol{R}$-Pt and $\boldsymbol{S}$-Pt exhibit $\boldsymbol{\lambda}_{\mathrm{EL}}$ of $540 \mathrm{~nm}$ and $\mathrm{EQE}_{\max }$ of $11.3 \%$ and $7.5 \%$, respectively, which indicates over $80 \%$ of IQE presuming the $\eta_{\text {out }}$ is $20 \%{ }^{45}$ Although there are examples of the use of both organic fluorescent and metal-based phosphorescent liquid crystals, to date there is only one recent report of a liquid crystalline TADF emitter. Bruce et al. presented the first two examples of TADF emitters showing liquid crystalline character by connecting alkoxy chains to the TADF emitting core 2,5-di( $N, N^{\prime}$-carbazolyl)terephthalonitrile (3b) or 2,3,5,6-tetra( $N, N^{\prime}$ carbazolyl)terephthalonitrile (4b). ${ }^{46}$ A columnar hexagonal mesophase is observed for $\mathbf{3 b}$ and $\mathbf{4 b}$, at $181{ }^{\circ} \mathrm{C}$ and $191{ }^{\circ} \mathrm{C}$, and both compounds exhibit delayed emission in toluene solution with delayed lifetimes of 5.5 $\mu \mathrm{s}$ and $1.0 \mu \mathrm{s}$, respectively. ${ }^{46}$ However, neither emitter orientation nor the use of these compounds in OLEDs were investigated. Janssen et al. tried to control the emitter orientation in solution-processed devices by doping emitters into a nematic LC host material poly(9,9-dioctylfluorene) (PFO), which can form horizontally aligned film after annealing. ${ }^{47}$ However, this host/guest system is only effective for certain $p$-phenylenevinylene oligomers and did not improve the orientation of the TADF emitter $\boldsymbol{t} \mathbf{B u}$ DACT-II, which shows the same vertical preferential (42\% vertical) orientation in solution-processed PFO or 2,2',2''-(benzene-1,3,5-triyl)tris(1-phenyl-1H-benzimidazole) (TPBi) films. ${ }^{47}$ These studies opened a new horizon for the use of liquid crystalline materials in OLEDs, especially in terms of the tuning of the film morphology and molecular orientation. 
Here, we report the first example of a liquid crystalline multi-resonant TADF (MR-TADF) emitter. The structure is based on our previously reported MR-TADF compound DiKTa, ${ }^{48}$ which was elaborated with mesogenic groups consisting of 1,6-dioxyhexyl-[1,1'-biphenyl]-4-carbonitrile chains. The compound DiKTaLC (Figure 1) exhibits MR-TADF character with delayed lifetime of $70.2 \mu \mathrm{s}$, and narrow emission spectra with $\mathrm{FWHM}=53 \mathrm{~nm}$ and $\lambda_{\mathrm{PL}}=514 \mathrm{~nm}$, as a neat thin film with a $\Phi_{\mathrm{PL}}$ of $41 \%$. The liquid crystalline character of DiKTaLC was confirmed by POM, DSC and Xray scattering as the material displays a nematic discotic mesophase between $80^{\circ} \mathrm{C}$ and $110^{\circ} \mathrm{C}$. The as-prepared spin-coated neat film of DiKTaLC shows preferential horizontal orientation with an anisotropy factor $a=0.26$ (74\% horizontal), which is preserved after annealing at $100^{\circ} \mathrm{C}$. 


\section{Previous luminous liquid crystals:}

Fluorescent emitter:

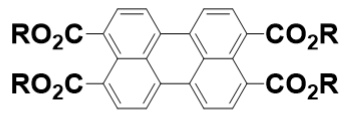

$$
\text { 3a-h }
$$

bipolar columnar liquid crystals Angew. Chem. Int. Ed., 2001, 40, 2060

Phosphorescent emitter:

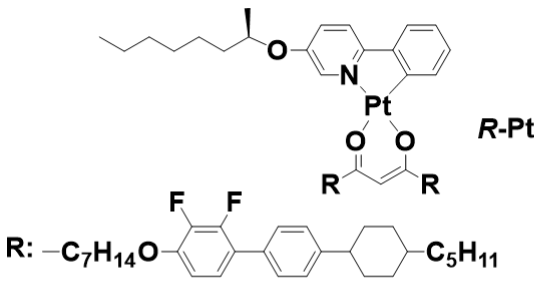

$\Phi_{\mathrm{PL}}: 74 \%, \mathrm{EQE}_{\max }: 11.3 \%, \lambda_{\mathrm{EL}}: 540 \mathrm{~nm}$

Adv. Optical Mater., 2020, 8, 2000775

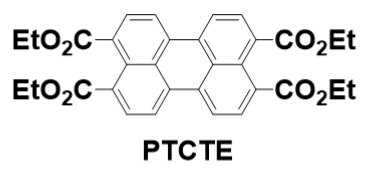

$\Phi_{\mathrm{PL}}: 14 \%, 72 \%$ horizontal orientation $\mathrm{EQE}_{\max }: 0.8 \%, \lambda_{\mathrm{EL}}: 580 \mathrm{~nm}$

Adv. Optical Mater., 2020, 8, 2000414

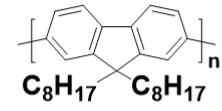

PFO

$\lambda_{\mathrm{PL}}: 450 \mathrm{~nm}$

$94 \%$ horizontal orientation

J. Mater. Chem. C, 2017, 5, 6555

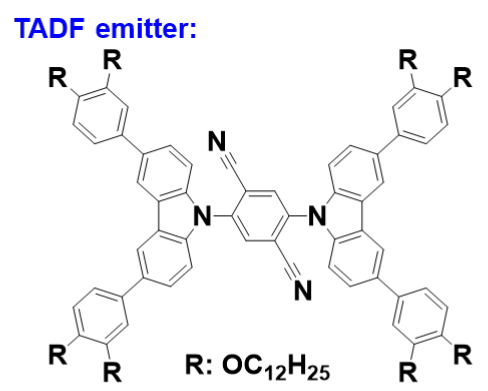

3b

$\Phi_{\mathrm{PL}}: 20 \%, \lambda_{\mathrm{PL}}: 560 \mathrm{~nm}, \tau_{\mathrm{d}}: 5.5 \mu \mathrm{s}$ J. Mater. Chem. C, 2021,9, 6528-6535

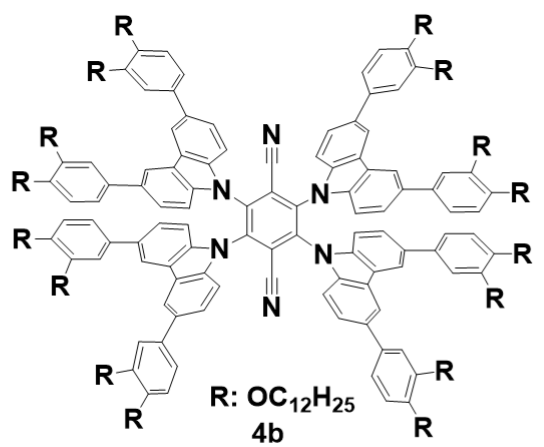

$\Phi_{\mathrm{PL}}: 4 \%, \lambda_{\mathrm{PL}}: 635 \mathrm{~nm}, \tau_{\mathrm{d}}: 1.0 \mu \mathrm{s}$

J. Mater. Chem. C, 2021,9, 6528-6535

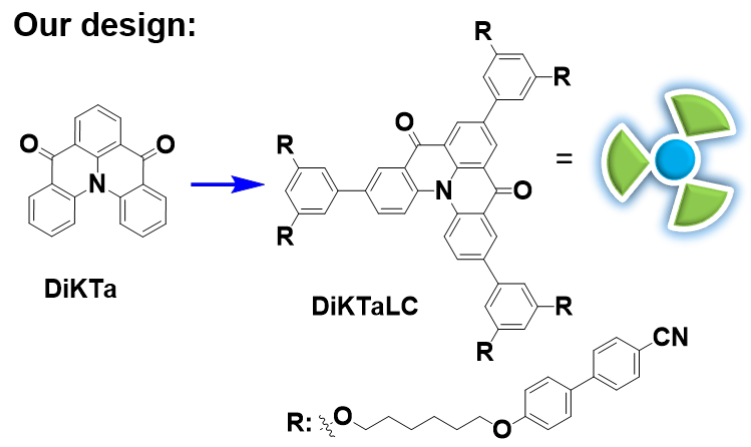

\section{MR-TADF character \\ Preferential horizontal orientation}

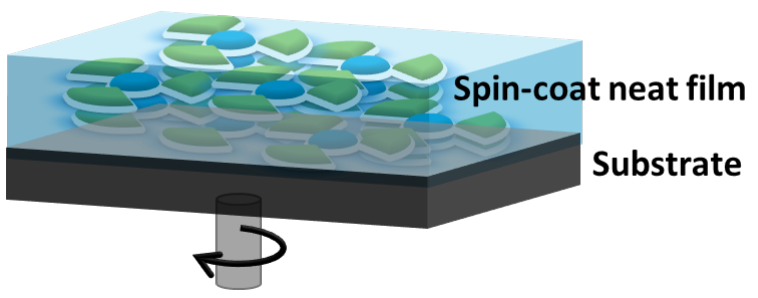

Figure 1. Molecular structures of previously reported luminous liquid crystals and our MR-TADF liquid crystal, DiKTaLC.

\section{Results and discussion}

\section{Computational Studies}

We first wished to establish the optoelectronic properties of the MR-TADF emitter core and how these differ from the reference compound, DiKTa. We thus modelled the optoelectronic properties of a model system, DiKTaPh(OMe)2, by spin-Component Scaling Coupled-Cluster second-order approximate 
coupled-cluster (SCS-CC2) calculations, which we have previously shown to be more accurate than timedependent density functional theory. ${ }^{49,50} \mathrm{We}$ also modelled the ground state electronic structure at the PBE0/6-31G(d,p) level of theory both DiKTaPh(OMe) $)_{2}$ and DiKTaLC. ${ }^{51,52}$ The electron density distribution of the HOMO and LUMO obtained by DFT of DiKTaPh(OMe $)_{2}$ and DiKTaLC are similar, while the difference density plots obtained by SCS-CC2 of DiKTaPh(OMe) 2 show the characteristic alternating pattern associated with MR-TADF compounds; the $S_{2}$ state possesses strong $n-\pi^{*}$ character. The alkyl-linked cyanobiphenyl units of DiKTaLC are not involved in the HOMO and LUMO distributions. The HOMO and LUMO energies of DiKTaPh(OMe $)_{2}$ are $-5.66 \mathrm{eV}$ and $-2.00 \mathrm{eV}$, respectively, while the HOMO energy of DiKTaLC is $0.17 \mathrm{eV}$ stabilized (-5.83 eV) and LUMO energy is $0.17 \mathrm{eV}$ stabilized ($2.17 \mathrm{eV}$ ) (Figure $\mathbf{S 1}$ ). As a result, the HOMO/LUMO energy gap $\left(\Delta \mathrm{E}_{\mathrm{g}}\right)$ is the same for both compounds at $3.66 \mathrm{eV}$ (Figure 2).

Using SCS-CC2/cc-pVDZ the energies of the $S_{1}$ and $T_{1}$ states of DiKTaPh(OMe $)_{2}$ are calculated to be $3.28 \mathrm{eV}$ and $3.03 \mathrm{eV}$, respectively, which are slightly stabilized compared to those of DiKTa $\left(\mathrm{S}_{1}=3.45 \mathrm{eV}\right.$, $\left.\mathrm{T}_{1}=3.18 \mathrm{eV}\right)$ or $\mathbf{M e s}_{3} \operatorname{DiKTa}\left(\mathrm{S}_{1}=3.32 \mathrm{eV}, \mathrm{T}_{1}=3.06 \mathrm{eV}\right)$, due to the similar inductive electron-accepting effect of the meta-disposed dimethoxyphenyl groups. ${ }^{48}$ The corresponding $\Delta \mathrm{E}_{\mathrm{ST}}$ of $\mathbf{D i K T a P h}(\mathbf{O M e})_{2}$ is $0.25 \mathrm{eV}$, which is modestly decreased compared to that of DiKTa and Mes $\mathbf{M}_{3}$ DiKTa $(0.27$ and $0.26 \mathrm{eV}$, respectively). ${ }^{48}$ Like DiKTa and Mes $_{3}$ DiKTa, the $\mathrm{T}_{1}$ and $\mathrm{S}_{1}$ states are short-range charge transfer (SRCT) excited states and the oscillator strength $(f)$ from $\mathrm{S}_{1}$ is predicted to be high $(0.22)$ for DiKTaPh(OMe), which reflects the significant overlap of the electron density distributions of the HOMO and LUMO of the short-range charge transfer excited state. The TDM vector of DiKTaPh(OMe $)_{2}$ in the $\mathrm{S}_{1}$ state is oriented with a small angle of $8.2^{\circ}$ to the plane of the molecule (X/Y plane in Figure $\mathbf{2 b}$ ), which is almost aligned with the X-axis. This result indicates that the likely TDM orientation of DiKTaLC highly co-aligns with the molecular orientation. 


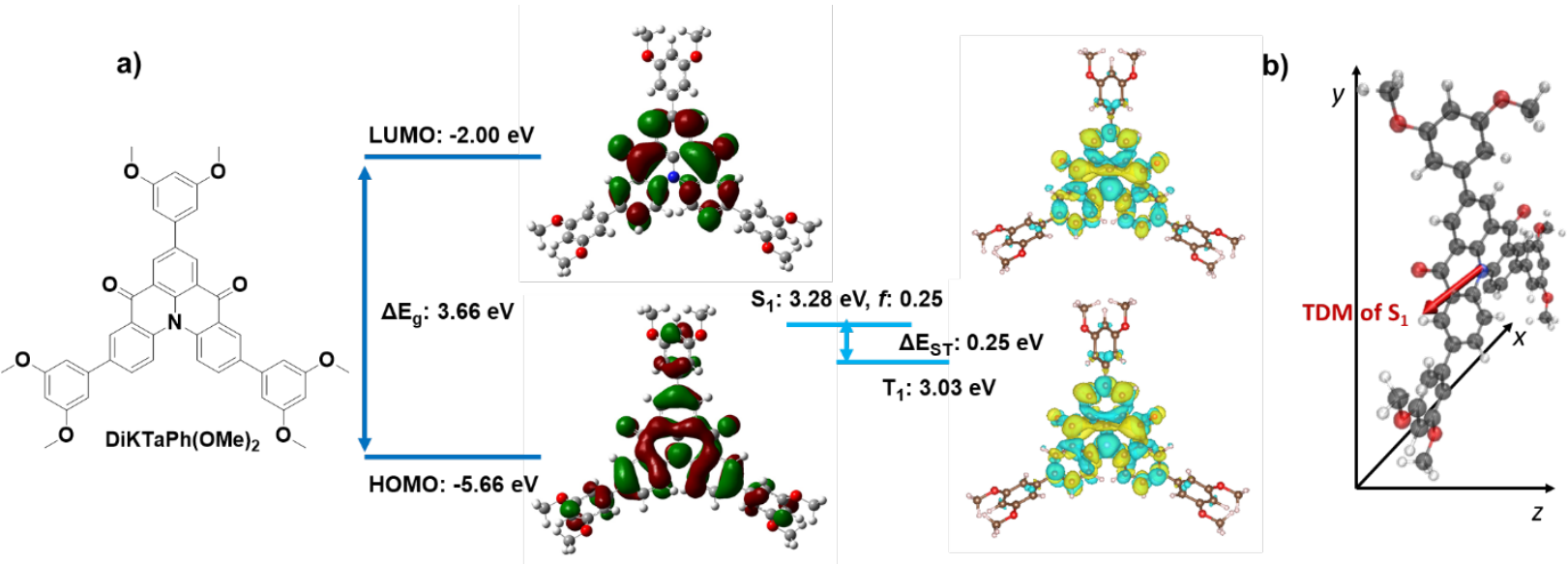

Figure 2. Isocontour plots of the HOMO and LUMO orbitals, frontier orbitals energy diagram, difference density plots and energies of the lowest singlet and triplet excited states for DiKTaPhOMe. b) $\mathrm{S}_{1}$ state TDM vector of DiKTaPhOMe.

\section{Synthesis}

The intermediate $\mathbf{B r} 3$ DiKTa was synthesized following our previously developed protocol, ${ }^{48}$ and this was coupled to the mesogenic group, BPinC6BPC, under Suzuki-Miyaura cross-coupling conditions in 68\% yield to afford DiKTaLC; the mesogenic BrC6BPC intermediate was obtained in three steps as outlined in Scheme 1. The identity and purity of the title compound were determined by a combination of ${ }^{1} \mathrm{H}$ and ${ }^{13} \mathrm{C}$ NMR spectroscopy, high resolution mass spectrometry, melting point, elemental analysis, and highperformance liquid chromatography. 


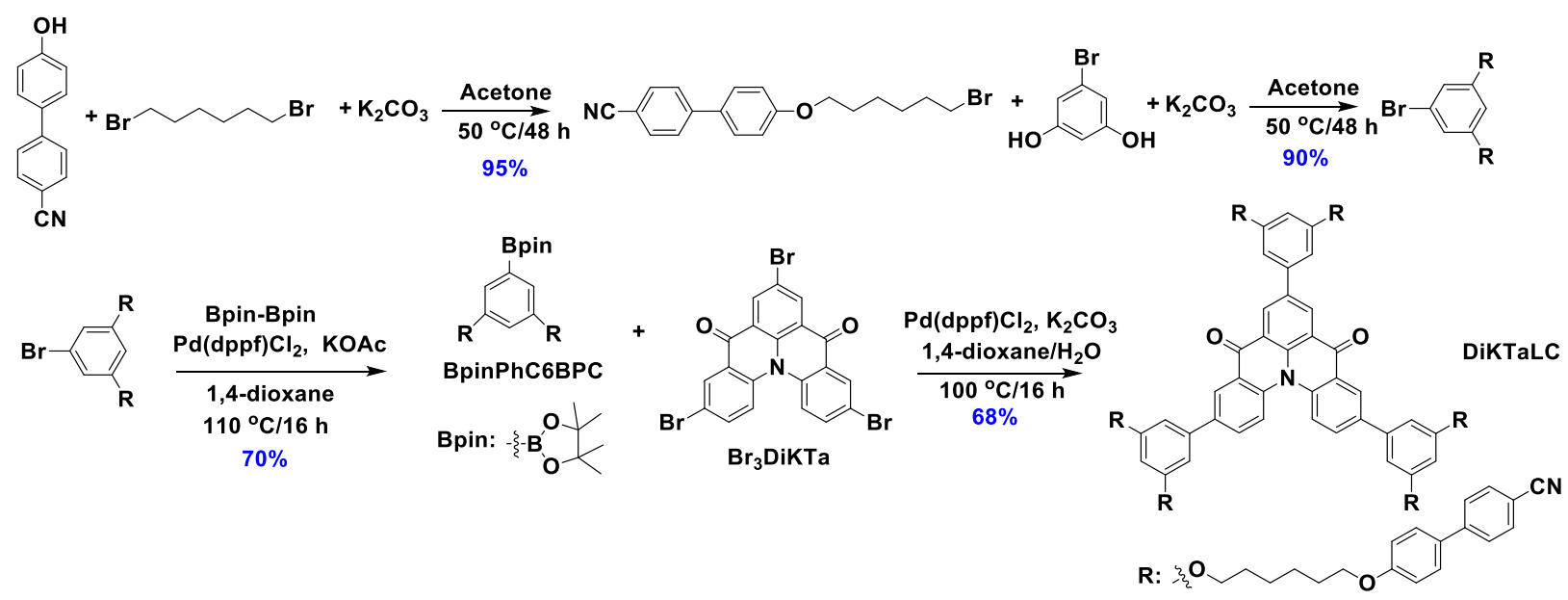

Scheme 1. Synthesis of DiKTaLC.

\section{Electrochemistry}

The electrochemical properties of DiKTaLC were investigated by cyclic voltammetry (CV) and differential pulse voltammetry (DPV) in DCM using tetrabutylammonium hexafluorophosphate $\left[\left(n-\mathrm{Bu}_{4} \mathrm{~N}\right) \mathrm{PF}_{6}\right]$ as the supporting electrolyte (Figure 3). The CV trace of DiKTaLC exhibits irreversible reduction and oxidation waves with $E^{\text {red }}$ of $-1.49 \mathrm{~V}$ and $E^{\text {ox }}$ at $1.34 \mathrm{~V}$ vs SCE, determined from the DPV. The corresponding HOMO and LUMO values for of DiKTaLC are -5.68 and -2.84 eV, respectively. Compared to the HOMO/LUMO values of -5.86/-3.26 for Mes $_{3}$ DiKTa, ${ }^{48}$ DiKTaLC shows more destabilized HOMO and LUMO values, which is ascribed to the electron-accepting properties of the peripheral groups and also match our DFT calculation. 


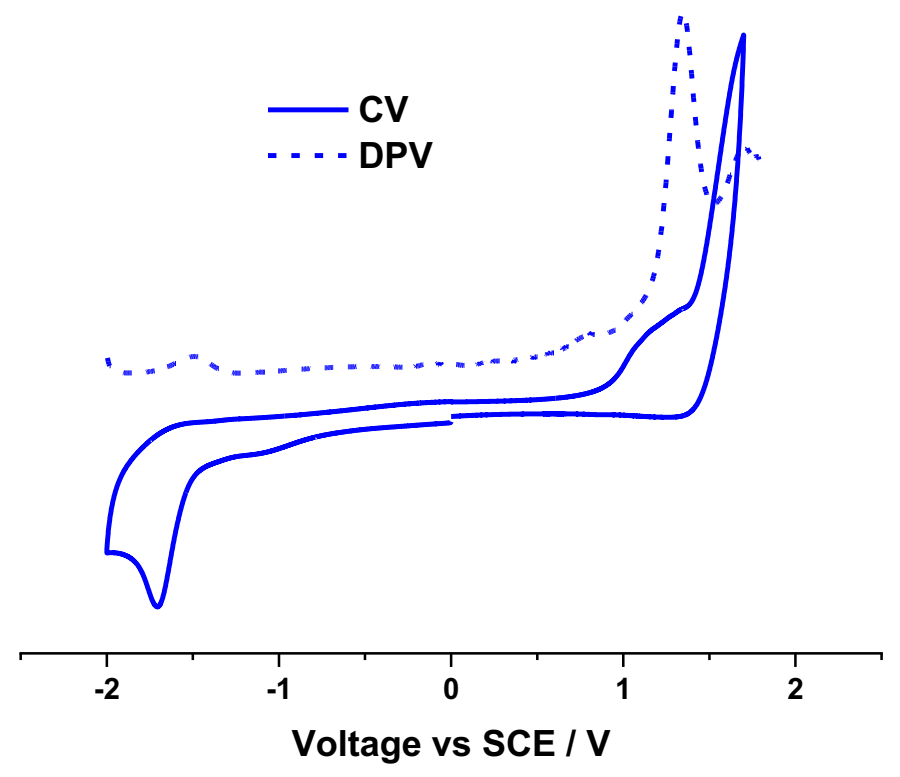

Figure 3. CV and DPV traces of DiKTaLC in DCM with $0.1 \mathrm{M} n-\mathrm{Bu}_{4} \mathrm{NPF}_{6}$ as the supporting electrolyte. Measured condition: scan rate $100 \mathrm{mV} / \mathrm{s}$, calibrated against a $\mathrm{Fc} / \mathrm{Fc}^{+}$redox couple and referenced to 0.46 V versus SCE. ${ }^{53}$

\section{Photophysical Properties}

The absorption spectrum in toluene of DiKTaLC (Figure 4a) mirrors those of DiKTa and Mes ${ }_{3}$ DiKTa with a low-energy band at $464 \mathrm{~nm}$ at a molar extinction coefficient $(\varepsilon)$ of around $20 \times 10^{3} \mathrm{M}^{-1} \mathrm{~cm}^{-1}$ associated with the SRCT state, ${ }^{48}$ and a high-intensity absorption $\left(\varepsilon>100 \times 10^{3} \mathrm{M}^{-1} \mathrm{~cm}^{-1}\right)$ band at $305 \mathrm{~nm}$ attributed to a superposition of locally excited (LE) $\pi-\pi^{*}$ transitions from the 4-cyanobiphenyl moieties and the DiKTa core. ${ }^{54}$ The photoluminescence (PL) spectrum of DiKTaLC in toluene shows a narrow emission band $(\mathrm{FWHM}=33 \mathrm{~nm})$ with an emission maximum, $\lambda_{\mathrm{PL}}$, of $487 \mathrm{~nm}$, and a small Stokes shift of $24 \mathrm{~nm}$. The photoluminescence quantum yield $\left(\Phi_{\mathrm{PL}}\right)$ of DiKTaLC is $39 \%$ in oxygen-free toluene, which is comparable to the $37 \%$ measured for Mes $_{3}$ DiKTa. ${ }^{48}$ DiKTaLC shows structured vibronic progression in nonpolar cyclohexane, whereas in higher polar solvents the emission becomes unstructured and narrowed, 
except in acetonitrile $(\mathrm{MeCN})$ where it is slightly broadened. The moderate positive solvatochromism is characteristic of MR-TADF compounds, which emit from a SRCT state (Figure 4b). Compared to structureless fluorescence spectra at room temperature in 2-methyl-tetrahydrofuran, the prompt fluorescence and phosphorescence spectra at $77 \mathrm{~K}$ show a more pronounced structured emission (Figure 4c). The $\mathrm{S}_{1}(2.74 \mathrm{eV})$ and $\mathrm{T}_{1}(2.55 \mathrm{eV})$ energies of DiKTaLC were determined from the onset of prompt fluorescence and phosphorescence spectra. The experimentally determined $\Delta \mathrm{E}_{\mathrm{ST}}$ of $0.19 \mathrm{eV}$ is close to the SCS-CC2 calculated value of $0.25 \mathrm{eV}$, which is sufficiently small to enable the RISC process. The timeresolved PL in degassed toluene (Figure 4d) shows a prompt fluorescence lifetime $\left(\tau_{\mathrm{p}}\right)$ of $7 \mathrm{~ns}$ and a delayed emission lifetime $\left(\tau_{\mathrm{d}}\right)$ of $1.0 \mu \mathrm{s}$, which is only a very small contribution $(0.5 \%)$ to the overall emission decay. 

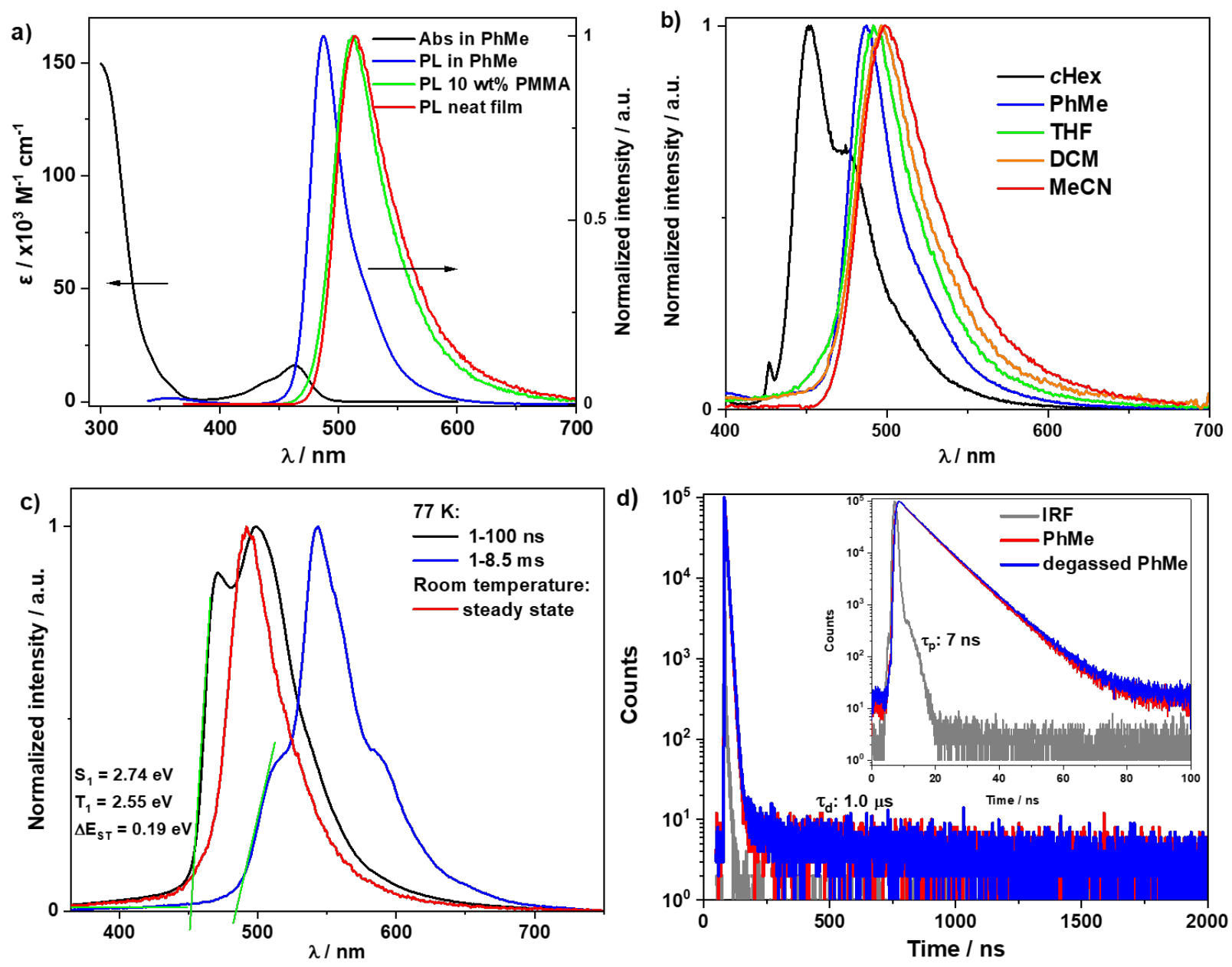

Figure 4. Photophysics of DiKTaLC in solutions. a) UV-vis absorption and photoluminescence spectra in solution $(\mathrm{PhMe})$ and thin film (10 wt $\%$ in PMMA and neat) $\lambda_{\mathrm{exc}}=340 \mathrm{~nm}$. b) Solvatochromic PL shift of DiKTaLC, $\lambda_{\mathrm{exc}}=340 \mathrm{~nm}$. c) Steady-state PL at room temperature, prompt PL at $77 \mathrm{~K}$ (delay: $1 \mathrm{~ns}$, gate: $100 \mathrm{~ns}$ ), and phosphorescence spectra at $77 \mathrm{~K}$ (delay: $1 \mathrm{~ms}$, gate: $8.5 \mathrm{~ms}$ ) in 2-methyl-tetrahydrofuran, $\lambda_{\text {exc }}$ $=343 \mathrm{~nm} . \mathrm{d}$ ) Time resolved PL of DiKTaLC in aerate and degassed toluene, $\lambda_{\mathrm{exc}}=379 \mathrm{~nm}$ and IRF is the instrument response function of the spectrometer.

We next measured the photophysical properties of DiKTaLC in $10 \mathrm{wt} \%$ doped polymethyl methacrylate (PMMA) and neat films. The $10 \mathrm{wt} \%$ doped films and neat films of DiKTaLC show almost identical emission spectra (Figure 4a) that are modestly red-shifted to $512 \mathrm{~nm}$ and $514 \mathrm{~nm}$, and slightly broadened 
with FWHM of $50 \mathrm{~nm}$ and $53 \mathrm{~nm}$, respectively, compared to the PL spectrum in toluene. The $\Phi_{\mathrm{PL}}$ values of DiKTaLC in $10 \mathrm{wt} \%$ doped PMMA films and neat films are 52\% and $41 \%$, respectively. The high $\Phi_{\mathrm{PL}}$ of DiKTaLC in the neat film indicates that the pendant mesogenic chains can readily suppress the concentration quenching previously observed for DiKTa, ${ }^{48}$ and further corroborated in our SAXS experiment. The $10 \mathrm{wt} \%$ doped PMMA films and neat films of DiKTaLC exhibit almost identical structured steady-state PL and phosphorescence spectra under $77 \mathrm{~K}$ (Figure 5a and 5b). The $\mathrm{S}_{1}$ and $\mathrm{T}_{1}$ energies of DiKTaLC in the solid state (both as doped and neat films), obtained from the onset of the prompt fluorescence $(\mathrm{PF})$ and phosphorescence spectra at $77 \mathrm{~K}$, are $2.48 \mathrm{eV}$ and $2.28 \mathrm{eV}$, respectively, which corresponds to a $\Delta \mathrm{E}_{\mathrm{ST}}$ of $0.20 \mathrm{eV}$. The time-resolved PL decays of DiKTaLC (Figures $\mathbf{5 c}$ and $\mathbf{5 d}$ ) exhibit the same $\tau_{\mathrm{p}}$ of $7 \mathrm{~ns}$ in both doped and neat films, while the average delayed emission lifetimes are 155.5 $\mu \mathrm{s}$ and 70.2 $\mu \mathrm{s}$, respectively, which are significantly longer than that observed in toluene (Figure $\mathbf{4 d}$ ). Temperature-dependent time-resolved PL decays reveal that the delayed emission is thermally activated in both doped and neat films. 

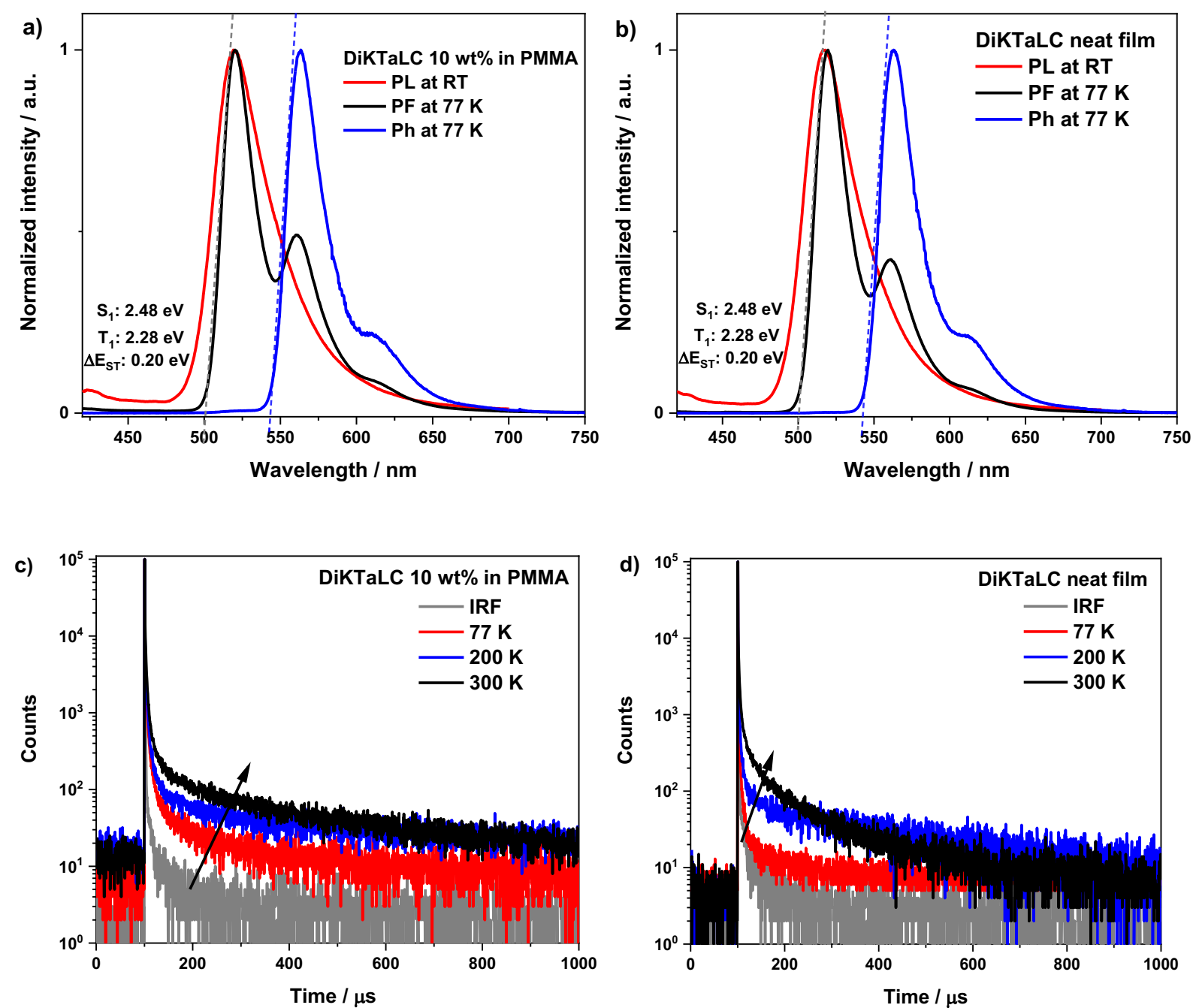

Figure 5. Steady-state PL spectra at room temperature and prompt fluorescence (PF) at $77 \mathrm{~K}$ (delay: $1 \mathrm{ns,}$ gate: $100 \mathrm{~ns}$ ), and phosphorescence spectra at $77 \mathrm{~K}$ (delay: $2 \mathrm{~ms}$, gate: $4 \mathrm{~ms}$ ) of a) $10 \mathrm{wt} \%$ doped PMMA film and b) neat film of DiKTaLC, $\left(\lambda_{\text {exc }}=390 \mathrm{~nm}\right)$; Temperature-dependent time-resolved PL decay spectra of c) $10 \mathrm{wt} \%$ doped PMMA film and d) neat film of DiKTaLC $\left(\lambda_{\mathrm{exc}}=379 \mathrm{~nm}\right)$.

\section{Thermotropic behavior}


DSC and POM were conducted to gain insight into the mesomorphic behavior of DiKTaLC. Upon heating the DSC trace of DiKTaLC exhibits a clearing point into the isotropic phase at $110{ }^{\circ} \mathrm{C}$ (Figure S2) with a clearing enthalpy of $-1.9 \mathrm{~kJ} \mathrm{~mol}^{-1}$ in the typical range for nematic discotic $\left(\mathrm{N}_{\mathrm{D}}\right)$ LCs. ${ }^{55,56}$ Investigation of DiKTaLC via POM revealed grainy (Figure 6a) and thread-like (Figure 6b) textures, which are typical for a $N_{D}$ phase upon cooling from the isotropic liquid. ${ }^{57,58}$ The textures showed laminar flow upon application of a shear force and vitrified below $80^{\circ} \mathrm{C}$.

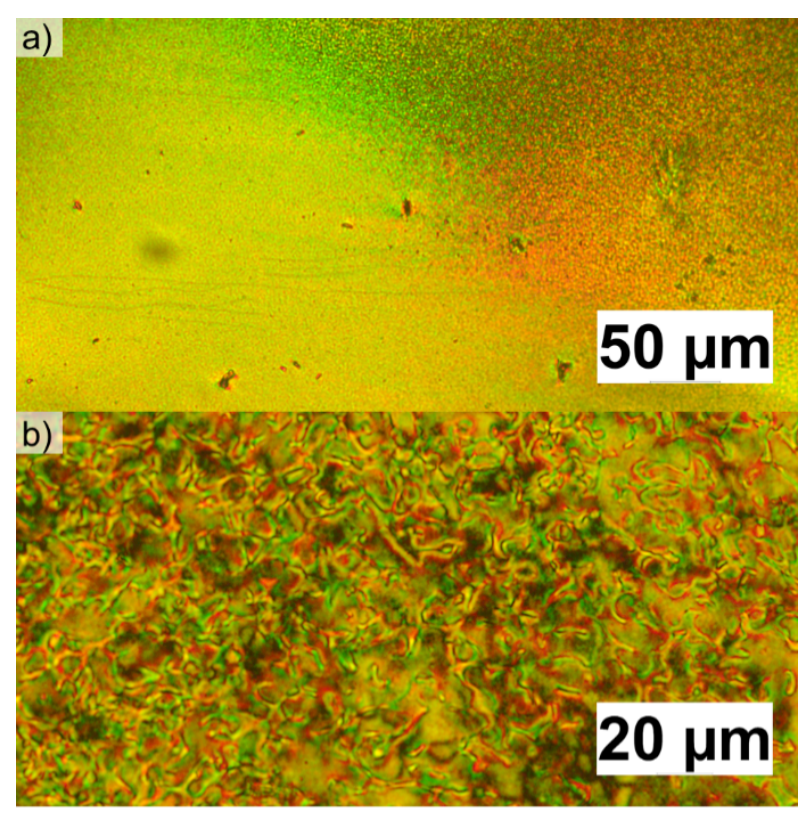

Figure 6. Micrographs of DiKTaLC obtained on the POM between crossed polarizers upon cooling from the isotropic phase (cooling rate: $1 \mathrm{~K} \mathrm{~min}^{-1}$ ) at a) $90{ }^{\circ} \mathrm{C}$ on glass slides and b) $110{ }^{\circ} \mathrm{C}$ on polyimide covered glass slides.

To characterize the mesophase of DiKTaLC in more detail, wide and small angle X-ray scattering (WAXS and SAXS) experiments were conducted. The 2D WAXS pattern of DiKTaLC at $97{ }^{\circ} \mathrm{C}$ (Figure 7a) featured a diffuse halo at $2 \theta=20.5^{\circ}\left(\mathrm{d}_{\text {halo }}=4.3 \AA\right)$ corresponding to the planar distance of the molecules. No $\pi-\pi$ reflex could be detected, thus ruling out columnar stacking of the DiKTaLC core in a columnar nematic $\left(\mathrm{N}_{\mathrm{Col}}\right)$ phase. ${ }^{55}$ The orthogonal alignment (Figure $\left.7 \mathbf{b}\right)$ of the wide and small angle reflexes and their 
diffuse nature (Figure 7a) were characteristic for a $\mathrm{N}_{\mathrm{D}}$ mesophase ${ }^{56}$ However, the occurrence of two small angle reflexes $\mathrm{q}_{1}$ and $\mathrm{q}_{2}$ around $2 \theta=2.5^{\circ}-5^{\circ}$ and corresponding to two lateral distances are unusual but not unknown for disordered $N_{D}$ phases. ${ }^{56,59}$
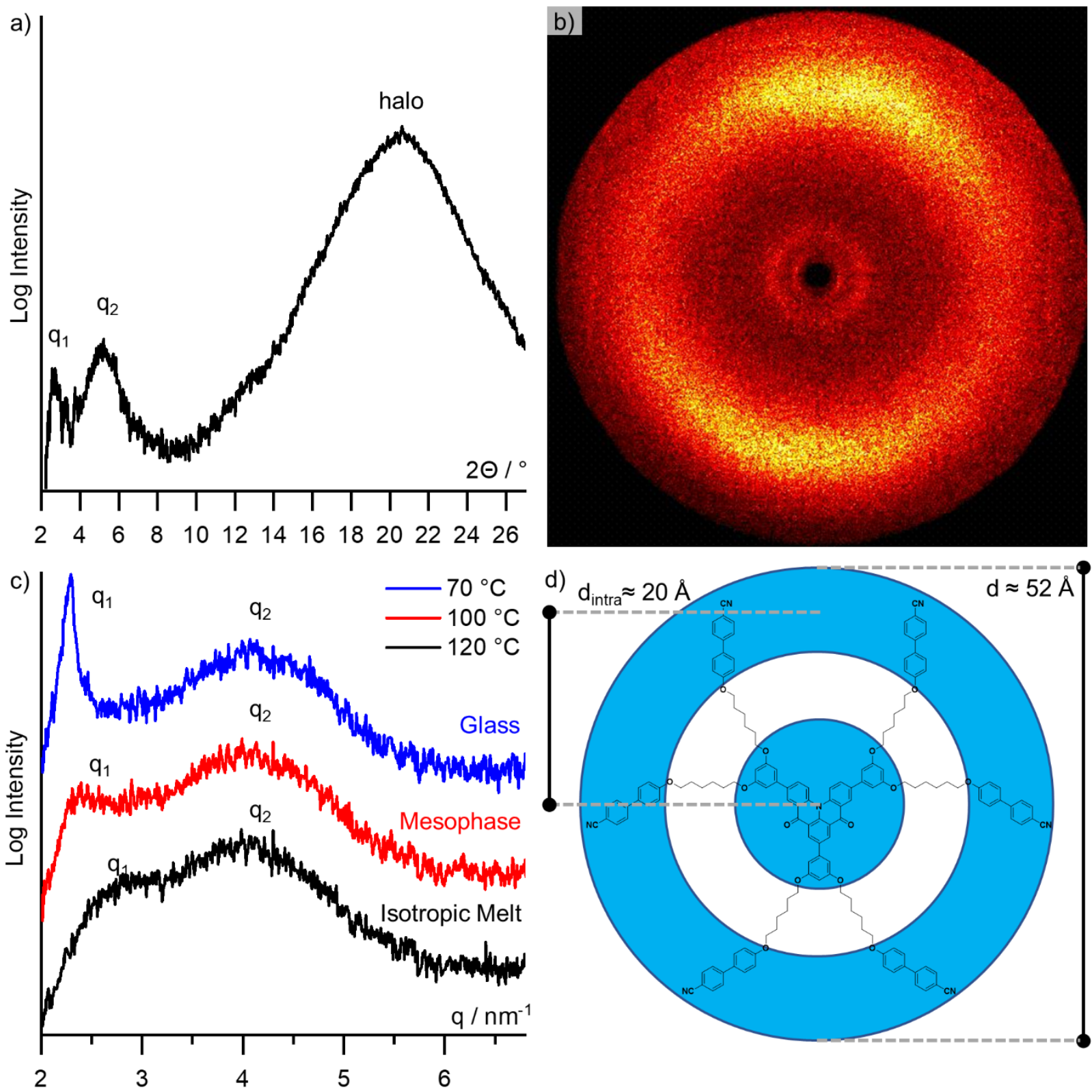

Figure 7. a) WAXS diffractogram of DiKTaLC recorded at $97{ }^{\circ} \mathrm{C}$ in a magnetic field upon heating, b) corresponding 2D WAXS pattern. c) 1D SAXS diffractograms recorded during cooling at $120^{\circ} \mathrm{C}, 100{ }^{\circ} \mathrm{C}$ 
and $70{ }^{\circ} \mathrm{C}$. d) Schematic model of DiKTaLC with molecular diameter $\mathrm{d}$ and intramolecular distance $\mathrm{d}_{\text {intra }}$ measured in Chem3D.

For better resolution of the small-angle section, temperature-dependent 1D SAXS experiments (Figure 7c) were performed on a Bruker SAXSess revealing two reflexes at $100{ }^{\circ} \mathrm{C}$ with $\mathrm{q}_{1}=1.83 \AA^{-1}\left(\mathrm{~d}_{1}=34.3 \AA\right)$ and $\mathrm{q}_{2}=3.60 \mathrm{~nm}^{-1}\left(\mathrm{~d}_{2}=17.5 \AA\right)$. Furthermore, $\mathrm{q}_{1}$ continuously increased and became less diffuse with decreasing temperature. The second reflex $\mathrm{q}_{2}$ was independent from the temperature and likely resulted from the intramolecular distance ${ }^{60} \mathrm{~d}_{\text {intra }} \approx 20 \AA$ (Figure 7 d) between the covalently linked cyanobiphenyl units and the aromatic core of DiKTaLC. Furthermore, $\mathrm{q}_{1}$ continuously decreased and became less diffuse with decreasing temperature (Figure $\mathbf{S 4}$ and Table S1). We conclude that $\mathrm{q}_{1}$ results from the lateral intermolecular distance within the $\mathrm{N}_{\mathrm{D}}$ phase. The associated distance $\mathrm{d}_{1}=34.3 \AA$ was considerably smaller than the calculated diameter of DiKTaLC d $\approx 52 \AA$ (Chem3D, all-trans conformation, Figure 7c) indicating strong mixing of the shape ambiphilic cyanobiphenyl "rods" and the disc like aromatic core of DiKTaLC in the $\mathrm{N}_{\mathrm{D}}$ mesophase. ${ }^{56,58,61-63}$ The mesophase structure is preserved in the glass phase as deduced from similar SAXS (Figure 7b) and WAXS patterns at $97^{\circ} \mathrm{C}$ and $69^{\circ} \mathrm{C}$ (Figure S3). This assumption is further supported by the observed suppression of concentration quenching in our photophysical investigations of the neat film, i.e., the aromatic cores seem to be isolated by the mixed rod-disk packing (vide supra).

\section{Orientation studies}

To quantitatively estimate the degree of DiKTaLC orientation in amorphous organic films, VASE and ARPL measurements were applied to neat films of DiKTaLC spin-coated from chloroform dilutions (see section S1 for details about sample preparation and measurements). The VASE and ARPL measurements were taken both before and after 1 hour of annealing the films at $100{ }^{\circ} \mathrm{C}$. 
The results of the VASE analysis are shown in Figure 9. The order parameter $(S)$ and anisotropy factor $(a)$ of the TDM of absorption in the films can be calculated from the local maxima of the extinction coefficients in the horizontal and vertical directions $\left(k_{\mathrm{o}}\right.$ and $\left.k_{\mathrm{e}}\right),{ }^{3,4}$

$$
S=\frac{k_{e}-k_{o}}{k_{e}+2 k_{o}}=\frac{3 a-1}{2}
$$

For an amorphous film, $a=0.33$ would correspond to perfectly isotropic orientation, while $a<0.33$ indicates a preferentially horizontal orientation. The VASE analysis shows that for an unannealed film, the values of $a$ for absorption at $290 \mathrm{~nm}$ and $475 \mathrm{~nm}$ (absorption bands of the cyano-biphenyl moieties and DiKTa core, respectively) are 0.20 and 0.29 , respectively. These values indicate $80 \%$ and $71 \%$ of horizontal orientation, respectively. For the annealed film, the TDM at $293 \mathrm{~nm}$ shows $94 \%$ of horizontal orientation $(a=0.06)$, and at $474 \mathrm{~nm}$ the TDM retains $69 \%$ of horizontal orientation $(a=0.31)$.

The orientation of the TDM of emission in the neat films was obtained separately by ARPL spectroscopy measurements, which probed only the emission from the DiKTa. The ARPL spectra were measured in a custom-built setup as described elsewhere. ${ }^{64}$ The resulting anisotropy factor $a$ was derived by fitting the ARPL spectra of the samples at the peak wavelength to an optical model based on the transfer-matrix method, ${ }^{65}$ which can provide a more accurate measurement of the orientation of the TDM of emission of the molecules..$^{3-5,66}$ Importantly, the anisotropic optical constants obtained from our ellipsometry measurements were used in this model to reflect the fact that the complex refractive index of the material shows non-negligible anisotropy. ${ }^{65}$ The PL spectra of the annealed films show a slight blue-shift in the peak wavelength and an increased PL intensity (Figure S10). As shown in Figure 10, both the pristine and annealed films exhibit preferential horizontal orientation with $a=0.26$, which is in good agreement with the result from VASE at $475 \mathrm{~nm}$. As the absorption at $290 \mathrm{~nm}$ mainly comes from the 4-cyanobiphenyl moieties of the mesogenic chains, the changes in the anisotropy factor observed by VASE indicate that there is mesogenic chain reorganization during the annealing process, which is characteristic of discotic liquid crystals, ${ }^{67}$ and is consistent with the POM measurements. While the absorption at $475 \mathrm{~nm}$ and the PL 
emission originate from the SRCT of the discotic emitting core, the consistency between the anisotropy factor measured by both VASE and ARPL spectroscopy measurements indicate that the long-range alignment of the discotic cores is preserved during the annealing process.
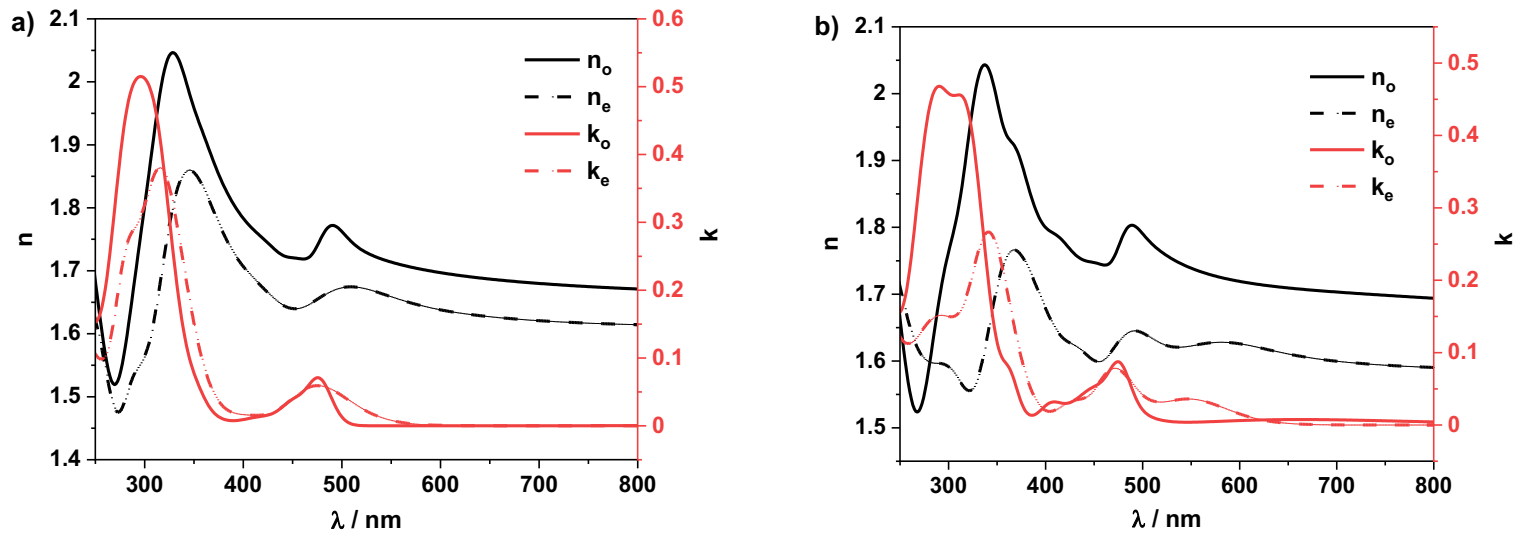

Figure 9. Anisotropic refractive indices and extinction coefficients of DiKTaLC neat film a) pristine and b) annealed. The black solid and dashed lines show the real component of the refractive indices in the horizontal and vertical directions $\left(n_{\mathrm{o}}\right.$ and $n_{\mathrm{e}}$ ), respectively. The red solid and dashed lines show the extinction coefficients in the horizontal and vertical directions $\left(k_{\mathrm{o}}\right.$ and $\left.k_{\mathrm{e}}\right)$, respectively.
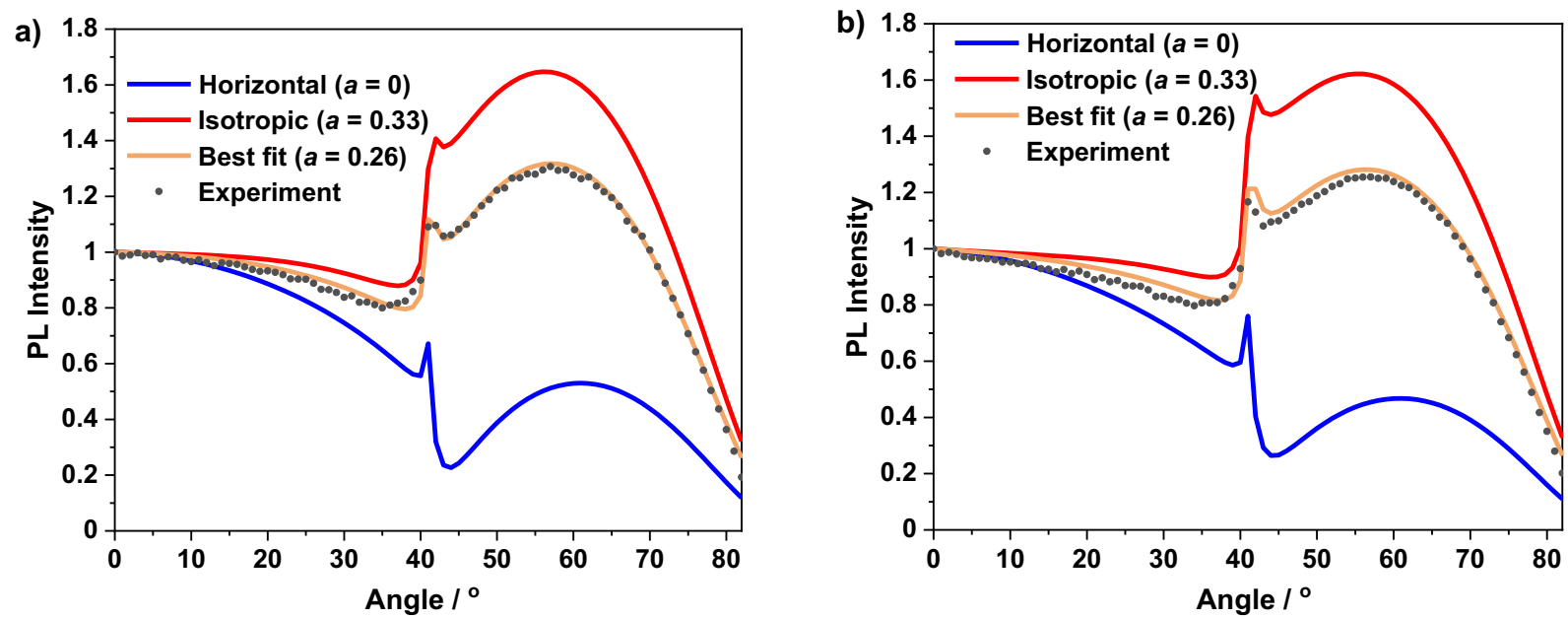

Figure 10. Angular dependence of the PL intensity at the peak emission wavelength of DiKTaLC films a) 
pristine and b) annealed. Gray symbols represent the experimental data; lines represent the modelled PL intensity for a perfect horizontal alignment of emitters (blue), for isotropic orientation (red), and for the best fit to the experimental data (orange). The corresponding anisotropy factors, $a$, for each line are indicated in the legends of each panel. All data sets were normalized to the corresponding intensity at $0^{\circ}$.

\section{Conclusions}

By attaching alkyl-tethered cyanobiphenyl units around a MR-TADF emitting core, DiKTaLC, exhibits the photophysical properties of a MR-TADF emitter such as narrowband green emission $\left(\lambda_{\mathrm{PL}}=514 \mathrm{~nm}\right.$, FWHM $=53 \mathrm{~nm})$, TADF, moderately high photoluminescence quantum yield $\left(\Phi_{\mathrm{PL}}\right.$ of $\left.41 \%\right)$ and additionally a $\mathrm{N}_{\mathrm{D}}$ mesophase between $80^{\circ} \mathrm{C}$ and $110^{\circ} \mathrm{C}$. The liquid crystalline properties of DiKTaLC were confirmed by POM, DSC, WAXS and SAXS measurements and the material vitrified in a glassy state below $80{ }^{\circ} \mathrm{C}$ retaining the disordered features of the $\mathrm{N}_{\mathrm{D}}$ mesophase. The as-prepared spin-coated neat film of DiKTaLC shows preferential horizontal orientation of the TDM and is resistant to thermal treatment. Our research shows that the distinct self-assembly of a liquid crystal can actually be harnessed to control the molecular TDM orientation in solution-processed films and devices and paves the way towards improved light outcoupling in solution-processed OLEDs.

\section{Acknowledgements}

The St Andrews team would also like to thank EPSRC (EP/P010482/1) and the Leverhulme Trust (RPG2016-047) for financial support. E.Z.-C. is a Royal Society Leverhulme Trust Senior Research Fellow (SRF\R1\201089). D.C thanks the China Scholarship Council (No. 201603780001). This project has received funding from the European Union's Horizon 2020 research and innovation programme under the Marie Skłodowska Curie grant agreement No 838885 (NarrowbandSSL) and S.M.S. acknowledges support 
for the Marie Skłodowska-Curie Individual Fellowship. Computational resources have been provided by the Consortium des Èquipements de Calcul Intensif (CE'CI), funded by the Fonds de la Recherche Scientifiques de Belgique (F. R. S.-FNRS) under Grant No. 2.5020.11, as well as the Tier-1 supercomputer of the Fédération Wallonie-Bruxelles, infrastructure funded by the Walloon. Y.O. acknowledges funding by the Fonds de la Recherche Scientifique-FNRS under Grant n F.4534.21 (MIS-IMAGINE). M.C.G. acknowledges support from the Alexander von Humboldt Foundation (Humboldt Professorship). A.M. acknowledges funding from the European Union's Horizon 2020 research and innovation programme under the Marie Skłodowska-Curie grant agreement No. 101023743 (PolDev). F.T.C. thanks Dr. Chang-Ki Moon for his support in the optical modelling with anisotropic optical constants. Generous financial support by the Studienstiftung des deutschen Volkes (Ph.D. fellowship for J.A.K.), the Ministerium für Wissenschaft, Forschung und Kunst des Landes Baden-Württemberg and the Carl Schneider Stiftung Aalen (shared instrumentation grant) are gratefully acknowledged. 


\section{References}

(1) Hong, G.; Gan, X.; Leonhardt, C.; Zhang, Z.; Seibert, J.; Busch, J. M.; Bräse, S. A Brief History of OLEDs—Emitter Development and Industry Milestones. Adv. Mater. 2021, 33 (9), 2005630. https://doi.org/10.1002/adma.202005630.

(2) Shibata, M.; Sakai, Y.; Yokoyama, D. Advantages and Disadvantages of Vacuum-Deposited and Spin-Coated Amorphous Organic Semiconductor Films for Organic Light-Emitting Diodes. $J$. Mater. Chem. C 2015, 3 (42), 11178-11191. https://doi.org/10.1039/c5tc01911g.

(3) Schmidt, T. D.; Lampe, T.; Daniel Sylvinson, M. R.; Djurovich, P. I.; Thompson, M. E.; Brütting, W. Emitter Orientation as a Key Parameter in Organic Light-Emitting Diodes. Phys. Rev. Appl. 2017, 8 (3), 1-28. https://doi.org/10.1103/PhysRevApplied.8.037001.

(4) Tenopala-Carmona, F.; Lee, O. S.; Crovini, E.; Neferu, A. M.; Murawski, C.; Olivier, Y.; ZysmanColman, E.; Gather, M. C. Identification of the Key Parameters for Horizontal Transition Dipole Orientation in Fluorescent and TADF Organic Light-Emitting Diodes. Adv. Mater. 2021, 33 (37), 2100677. https://doi.org/10.1002/adma.202100677.

(5) Kim, K. H.; Kim, J. J. Origin and Control of Orientation of Phosphorescent and TADF Dyes for High-Efficiency OLEDs. Adv. Mater. 2018, 30 (42), 1705600. https://doi.org/10.1002/adma.201705600.

(6) Huang, T.; Jiang, W.; Duan, L. Recent Progress in Solution Processable TADF Materials for Organic Light-Emitting Diodes. J. Mater. Chem. C 2018, 6 (21), 5577-5596. https://doi.org/10.1039/c8tc01139g.

(7) Cho, Y. J.; Yook, K. S.; Lee, J. Y. High Efficiency in a Solution-Processed Thermally Activated Delayed-Fluorescence Device Using a Delayed-Fluorescence Emitting Material with Improved Solubility. Adv. Mater. 2014, 26 (38), 6642-6646. https://doi.org/10.1002/adma.201402188. 
(8) Wada, Y.; Kubo, S.; Kaji, H. Adamantyl Substitution Strategy for Realizing Solution-Processable Thermally Stable Deep-Blue Thermally Activated Delayed Fluorescence Materials. Adv. Mater. 2018, 30 (8), 1705641. https://doi.org/10.1002/adma.201705641.

(9) Shao, S.; Hu, J.; Wang, X.; Wang, L.; Jing, X.; Wang, F. Blue Thermally Activated Delayed Fluorescence Polymers with Nonconjugated Backbone and Through-Space Charge Transfer Effect. J. Am. Chem. Soc. 2017, 139 (49), 17739-17742. https://doi.org/10.1021/jacs.7b10257.

(10) Albrecht, K.; Matsuoka, K.; Fujita, K.; Yamamoto, K. Carbazole Dendrimers as SolutionProcessable Thermally Activated Delayed-Fluorescence Materials. Angew. Chemie - Int. Ed. 2015, 54 (19), 5677-5682. https://doi.org/10.1002/anie.201500203.

(11) Pal, A. K.; Krotkus, S.; Fontani, M.; Mackenzie, C. F. R.; Cordes, D. B.; Slawin, A. M. Z.; Samuel, I. D. W.; Zysman-Colman, E. High-Efficiency Deep-Blue-Emitting Organic LightEmitting Diodes Based on Iridium(III) Carbene Complexes. Adv. Mater. 2018, 30 (50), 1-10. https://doi.org/10.1002/adma.201804231.

(12) Song, J.; Lee, H.; Jeong, E. G.; Choi, K. C.; Yoo, S. Organic Light-Emitting Diodes: Pushing Toward the Limits and Beyond. Adv. Mater. 2020, 32 (35), 1907539. https://doi.org/10.1002/adma.201907539.

(13) Wong, M. Y.; Zysman-Colman, E. Purely Organic Thermally Activated Delayed Fluorescence Materials for Organic Light-Emitting Diodes. Adv. Mater. 2017, 29 (22), 1605444. https://doi.org/10.1002/adma.201605444.

(14) Uoyama, H.; Goushi, K.; Shizu, K.; Nomura, H.; Adachi, C. Highly Efficient Organic LightEmitting Diodes from Delayed Fluorescence. Nature 2012, 492 (7428), 234-238. https://doi.org/10.1038/nature11687.

(15) Cui, L.; Gillett, A. J.; Zhang, S.; Ye, H.; Liu, Y.; Chen, X.; Lin, Z.; Evans, E. W.; Myers, W. K.; 
Ronson, T. K.; Nakanotani, H.; Reineke, S.; Bredas, J.; Adachi, C.; Friend, R. H. Fast Spin-Flip Enables Efficient and Stable Organic Electroluminescence from Charge-Transfer States. Nat. Photon. 2020, 14, 636-642. https://doi.org/http://dx.doi.org/10.1038/s41566-020-0668-z.

(16) Naqvi, B. A.; Schmid, M.; Crovini, E.; Sahay, P.; Naujoks, T.; Rodella, F.; Zhang, Z.; Strohriegl, P.; Bräse, S.; Zysman-Colman, E.; Brütting, W. What Controls the Orientation of TADF Emitters? Front. Chem. 2020, 8, 750. https://doi.org/10.3389/fchem.2020.00750.

(17) Lu, J.; Zheng, Y.; Zhang, J. Tuning the Color of Thermally Activated Delayed Fluorescent Properties for Spiro-Acridine Derivatives by Structural Modification of the Acceptor Fragment: A DFT Study. RSC Adv. 2015, 5 (24), 18588-18592. https://doi.org/10.1039/C4RA15155K.

(18) Frischeisen, J.; Yokoyama, D.; Endo, A.; Adachi, C.; Brütting, W. Increased Light Outcoupling Efficiency in Dye-Doped Small Molecule Organic Light-Emitting Diodes with Horizontally Oriented Emitters. Org. Electron. 2011, 12 (5), 809-817. https://doi.org/10.1016/j.orgel.2011.02.005.

(19) Yokoyama, D. Molecular Orientation in Small-Molecule Organic Light-Emitting Diodes. J. Mater. Chem. 2011, 21 (48), 19187. https://doi.org/10.1039/c1jm13417e.

(20) Kim, K. H.; Lee, S.; Moon, C. K.; Kim, S. Y.; Park, Y. S.; Lee, J. H.; Lee, J. W.; Huh, J.; You, Y.; Kim, J. J. Phosphorescent Dye-Based Supramolecules for High-Efficiency Organic Light-Emitting Diodes. Nat. Commun. 2014, 5, 4769. https://doi.org/10.1038/ncomms5769.

(21) Keum, C.; Becker, D.; Archer, E.; Bock, H.; Kitzerow, H.; Gather, M. C.; Murawski, C. Organic Light-Emitting Diodes Based on a Columnar Liquid-Crystalline Perylene Emitter. Adv. Opt. Mater. 2020, 8 (17), 2000414. https://doi.org/10.1002/adom.202000414.

(22) Yokoyama, D.; Sakaguchi, A.; Suzuki, M.; Adachi, C. Horizontal Orientation of Linear-Shaped Organic Molecules Having Bulky Substituents in Neat and Doped Vacuum-Deposited Amorphous 
Films. Org. Electron. 2009, 10 (1), 127-137. https://doi.org/10.1016/j.orgel.2008.10.010.

(23) Yokohama, D.; Setoguchi, Y.; Sakaguchi, A.; Suzuki, M.; Adachi, C. Orientation Control of Linear-Shaped Molecules in Vacuum-Deposited Organic Amorphous Films and Its Effect on Carrier Mobilities. Adv. Funct. Mater. 2010, 20 (3), 386-391.

https://doi.org/10.1002/adfm.200901684.

(24) Yokoyama, D.; Sasabe, H.; Furukawa, Y.; Adachi, C.; Kido, J. Molecular Stacking Induced by Intermolecular C-H $\cdots \mathrm{N}$ Hydrogen Bonds Leading to High Carrier Mobility in Vacuum-Deposited Organic Films. Adv. Funct. Mater. 2011, 21 (8), 1375-1382. https://doi.org/10.1002/adfm.201001919.

(25) Watanabe, Y.; Yokoyama, D.; Koganezawa, T.; Katagiri, H.; Ito, T.; Ohisa, S.; Chiba, T.; Sasabe, H.; Kido, J. Control of Molecular Orientation in Organic Semiconductor Films Using Weak Hydrogen Bonds. Adv. Mater. 2019, 31, 1808300. https://doi.org/10.1002/adma.201808300.

(26) Flámmich, M.; Gather, M. C.; Danz, N.; Michaelis, D.; Bráuer, A. H.; Meerholz, K.; Tünnermann, A. Orientation of Emissive Dipoles in OLEDs: Quantitative in Situ Analysis. Org. Electron. 2010, 11 (6), 1039-1046. https://doi.org/10.1016/j.orgel.2010.03.002.

(27) Kim, J. S.; Ho, P. K. H.; Greenham, N. C.; Friend, R. H. Electroluminescence Emission Pattern of Organic Light-Emitting Diodes: Implications for Device Efficiency Calculations. J. Appl. Phys. 2000, 88 (2), 1073-1081. https://doi.org/10.1063/1.373779.

(28) McBranch, D.; Campbell, I. H.; Smith, D. L.; Ferraris, J. P. Optical Determination of Chain Orientation in Electroluminescent Polymer Films. Appl. Phys. Lett. 1995, 1175 (October 1994), 1175. https://doi.org/10.1063/1.113848.

(29) Kim, N. S.; Kim, D. Y.; Song, J. H.; Suh, M. C. Improvement of Viewing Angle Dependence of Bottom-Emitting Green Organic Light-Emitting Diodes with a Strong Microcavity Effect. Opt. 
Express 2020, 28 (21), 31686. https://doi.org/10.1364/oe.403398.

(30) Lampe, T.; Schmidt, T. D.; Jurow, M. J.; Djurovich, P. I.; Thompson, M. E.; Brütting, W. Dependence of Phosphorescent Emitter Orientation on Deposition Technique in Doped Organic Films. Chem. Mater. 2016, 28 (3), 712-715. https://doi.org/10.1021/acs.chemmater.5b04607.

(31) Kaji, H.; Suzuki, H.; Fukushima, T.; Shizu, K.; Suzuki, K.; Kubo, S.; Komino, T.; Oiwa, H.; Suzuki, F.; Wakamiya, A.; Murata, Y.; Adachi, C. Purely Organic Electroluminescent Material Realizing 100\% Conversion from Electricity to Light. Nat. Commun. 2015, 6, 8476. https://doi.org/10.1038/ncomms9476.

(32) Suzuki, K.; Adachi, C.; Kaji, H. Solution-Processable Thermally Activated Delayed Fluorescence Emitters for Application in Organic Light Emitting Diodes. J. Soc. Inf. Disp. 2017, 25 (8), 480485. https://doi.org/10.1002/jsid.598.

(33) Herbst, S.; Soberats, B.; Leowanawat, P.; Lehmann, M.; Würthner, F. A Columnar Liquid-Crystal Phase Formed by Hydrogen-Bonded Perylene Bisimide J-Aggregates. Angew. Chemie - Int. Ed. 2017, 56 (8), 2162-2165. https://doi.org/10.1002/anie.201612047.

(34) Chen, Z.; Baumeister, U.; Tschierske, C.; Würthner, F. Effect of Core Twisting on Self-Assembly and Optical Properties of Perylene Bisimide Dyes in Solution and Columnar Liquid Crystalline Phases. Chem. - A Eur. J. 2007, 13 (2), 450-465. https://doi.org/10.1002/chem.200600891.

(35) Eccher, J.; Faria, G. C.; Bock, H.; Von Seggern, H.; Bechtold, I. H. Order Induced Charge Carrier Mobility Enhancement in Columnar Liquid Crystal Diodes. ACS Appl. Mater. Interfaces 2013, 5 (22), 11935-11943. https://doi.org/10.1021/am403681q.

(36) Keum, C. M.; Liu, S.; Al-Shadeedi, A.; Kaphle, V.; Callens, M. K.; Han, L.; Neyts, K.; Zhao, H.; Gather, M. C.; Bunge, S. D.; Twieg, R. J.; Jakli, A.; Lüssem, B. Tuning Charge Carrier Transport and Optical Birefringence in Liquid-Crystalline Thin Films: A New Design Space for Organic 
Light-Emitting Diodes. Sci. Rep. 2018, 8, 699. https://doi.org/10.1038/s41598-018-19157-9.

Liao, X.; Kahle, F. J.; Liu, B.; Bässler, H.; Zhang, X.; Köhler, A.; Greiner, A. Polarized Blue Photoluminescence of Mesoscopically Ordered Electrospun Non-Conjugated Polyacrylonitrile Nanofibers. Mater. Horizons 2020, 7 (6), 1605-1612. https://doi.org/10.1039/d0mh00002g.

Bala, I.; Singh, N.; Yadav, R. A. K.; De, J.; Gupta, S. P.; Singh, D. P.; Dubey, D. K.; Jou, J. H.; Douali, R.; Pal, S. K. Room Temperature Perylene Based Columnar Liquid Crystals as Solid-State Fluorescent Emitters in Solution-Processable Organic Light-Emitting Diodes. J. Mater. Chem. C 2020, 8 (36), 12485-12494. https://doi.org/10.1039/d0tc02754e.

Bala, I.; Yang, W. Y.; Gupta, S. P.; De, J.; Yadav, R. A. K.; Singh, D. P.; Dubey, D. K.; Jou, J. H.; Douali, R.; Pal, S. K. Room Temperature Discotic Liquid Crystalline TriphenylenePentaalkynylbenzene Dyads as an Emitter in Blue OLEDs and Their Charge Transfer Complexes with Ambipolar Charge Transport Behaviour. J. Mater. Chem. C 2019, 7 (19), 5724-5738. https://doi.org/10.1039/c9tc01178a.

(40) De, J.; Abdul, A. H.; Yadav, R. A. K.; Gupta, S. P.; Bala, I.; Chawla, P.; Kesavan, K. K.; Jou, J. H.; Pal, S. K. AIE-Active Mechanoluminescent Discotic Liquid Crystals for Applications in OLEDs and Bio-Imaging. Chem. Commun. 2020, 56 (91), 14279-14282. https://doi.org/10.1039/d0cc05813k.

(41) Hassheider, T.; Benning, S. A.; Kitzerow, H.-S.; Achard, M.-F.; Bock, H. Color-Tuned Electroluminescence from Columnar Liquid Crystalline Alkyl Arenecarboxylates. Angew. Chem. Int. Ed. 2001, 40, 2060-2063. https://doi.org/https://doi.org/10.1002/15213773(20010601)40:11<2060::AID-ANIE2060>3.0.CO;2-H.

(42) Seguy, I.; Destruel, P.; Bock, H. All-Columnar Bilayer Light-Emitting Diode. Synth. Met. 2000, 111, 15-18. https://doi.org/10.1016/S0379-6779(99)00405-1. 
(43) Liu, S. H.; Lin, M. S.; Chen, L. Y.; Hong, Y. H.; Tsai, C. H.; Wu, C. C.; Poloek, A.; Chi, Y.; Chen, C. A.; Chen, S. H.; Hsu, H. F. Polarized Phosphorescent Organic Light-Emitting Devices Adopting Mesogenic Host-Guest Systems. Org. Electron. 2011, 12 (1), 15-21. https://doi.org/10.1016/j.orgel.2010.09.020.

(44) Wang, Y.; Fan, J.; Shi, J.; Qi, H.; Baranoff, E.; Xie, G.; Li, Q.; Tan, H.; Liu, Y.; Zhu, W. Influence of Integrated Alkyl-Chain Length on the Mesogenic and Photophysical Properties of PlatinumBased Metallomesogens and Their Application for Polarized White OLEDs. Dye. Pigment. 2016, 133, 238-247. https://doi.org/10.1016/j.dyepig.2016.05.024.

(45)

Qian, G.; Yang, X.; Wang, X.; Herod, J. D.; Bruce, D. W.; Wang, S.; Zhu, W.; Duan, P.; Wang, Y. Chiral Platinum-Based Metallomesogens with Highly Efficient Circularly Polarized Electroluminescence in Solution-Processed Organic Light-Emitting Diodes. Adv. Opt. Mater. 2020, 8 (20), 2000775. https://doi.org/10.1002/adom.202000775.

(46) Suleymanova, A. F.; Shafikov, M. Z.; Whitwood, A. C.; Czerwieniec, R.; Bruce, D. W. LiquidCrystalline TADF Materials Based on Substituted Carbazoles and Terephthalonitrile. J. Mater. Chem. C 2021, 9 (20), 6528-6535. https://doi.org/10.1039/d1tc00443c.

(47) Senes, A.; Meskers, S. C. J.; Greiner, H.; Suzuki, K.; Kaji, H.; Adachi, C.; Wilson, J. S.; Janssen, R. A. J. Increasing the Horizontal Orientation of Transition Dipole Moments in Solution Processed Small Molecular Emitters. J. Mater. Chem. C 2017, 5 (26), 6555-6562. https://doi.org/10.1039/C7TC01568B.

(48) Hall, D.; Suresh, S. M.; dos Santos, P. L.; Duda, E.; Bagnich, S.; Pershin, A.; Rajamalli, P.; Cordes, D. B.; Slawin, A. M. Z.; Beljonne, D.; Köhler, A.; Samuel, I. D. W.; Olivier, Y.; ZysmanColman, E. Improving Processability and Efficiency of Resonant TADF Emitters: A Design Strategy. Adv. Opt. Mater. 2020, 8, 1901627. https://doi.org/10.1002/adom.201901627.

(49) Pershin, A.; Hall, D.; Lemaur, V.; Sancho-Garcia, J. C.; Muccioli, L.; Zysman-Colman, E.; 
Beljonne, D.; Olivier, Y. Highly Emissive Excitons with Reduced Exchange Energy in Thermally Activated Delayed Fluorescent Molecules. Nat. Commun. 2019, 10, 597.

https://doi.org/10.1038/s41467-019-08495-5.

(50) Suresh, S. M.; Duda, E.; Hall, D.; Yao, Z.; Bagnich, S.; Slawin, A. M. Z.; Bässler, H.; Beljonne, D.; Buck, M.; Olivier, Y.; Köhler, A.; Zysman-Colman, E. A Deep Blue B,N-Doped Heptacene Emitter That Shows Both Thermally Activated Delayed Fluorescence and Delayed Fluorescence by Triplet-Triplet Annihilation. J. Am. Chem. Soc. 2020, 142 (14), 6588-6599. https://doi.org/10.1021/jacs.9b13704.

(51) Pople, J. A.; Binkley, J. S.; Seeger, R. Theoretical Models Incorporating Electron Correlation. Int. J. Quantum Chem. 1976, 10, 1-19. https://doi.org/10.1002/qua.560100802.

(52) Adamo, C. Toward Reliable Density Functional Methods without Adjustable Parameters : The PBE0 Model. J. Chem. Phys. 1999, 110, 6158-6170.

https://doi.org/https://doi.org/10.1063/1.478522.

(53) Connelly, N. G.; Geiger, W. E. Chemical Redox Agents for Organometallic Chemistry. Chem. Rev. 1996, 96 (2), 877-910. https://doi.org/10.1021/cr940053x.

(54) Mishra, M.; Dabrowski, R. S.; Vij, J. K.; Mishra, A.; Dhar, R. Electrical and Electro-Optical Parameters of 4'-Octyl-4-Cyanobiphenyl Nematic Liquid Crystal Dispersed with Gold and Silver Nanoparticles. Liq. Cryst. 2015, 42 (11), 1580-1590.

https://doi.org/10.1080/02678292.2015.1071438.

(55) Kouwer, P. H. J.; Jager, W. F.; Mijs, W. J.; Picken, S. J. The Nematic Lateral Phase: A Novel Phase in Discotic Supramolecular Assemblies [4]. Macromolecules 2001, 34 (22), 7582-7584. https://doi.org/10.1021/ma011007j.

(56) Kouwer, P. H. J.; Mehl, G. H. Hierarchical Organisation in Shape-Amphiphilic Liquid Crystals. J. 
Mater. Chem. 2009, 19 (11), 1564-1575. https://doi.org/10.1039/b819877b.

(57) Fletcher, I. D.; Luckhurst, G. R. The Synthesis and Characterization of Novel Non-Symmetric Dimers with Rod-like and Disc-like Mesogenic Units. Liq. Cryst. 1995, 18 (2), 175-183. https://doi.org/10.1080/02678299508036611.

(58) Kouwer, P. H. J.; Mehl, G. H. Nematic Phases of Disc-and Rod-Shaped Molecules. Mol. Cryst. Liq. Cryst. 2003, 397, 301-316. https://doi.org/10.1080/714965609.

Li, J.; Wang, J. H.; Cao, X. J.; Li, X. D.; Ren, X. K.; Yu, Z. Q. Peripherally Modified Tetraphenylethene: Emerging as a Room-Temperature Luminescent Disc-Like Nematic Liquid Crystal. ACS Appl. Mater. Interfaces 2021, 13 (29), 35207-35213.

https://doi.org/10.1021/acsami.1c10243.

(60) Gupta, M.; Gupta, S. P.; Rasna, M. V.; Adhikari, D.; Dhara, S.; Pal, S. K. A New Strategy towards the Synthesis of a Room-Temperature Discotic Nematic Liquid Crystal Employing Triphenylene and Pentaalkynylbenzene Units. Chem. Commun. 2017, 53 (21), 3014-3017. https://doi.org/10.1039/c6cc09509g.

(61) Kouwer, P. H. J.; Mehl, G. H. Multiple Levels of Order in Linked Disc-Rod Liquid Crystals. Angew. Chemie - Int. Ed. 2003, 42 (48), 6015-6018. https://doi.org/10.1002/anie.200352488.

(62) Kouwer, P. H. J.; Mehl, G. H. Full Miscibility of Disk- and Rod-Shaped Mesogens in the Nematic Phase. J. Am. Chem. Soc. 2003, 125 (37), 11172-11173. https://doi.org/10.1021/ja037075y.

(63) Imrie, C. T.; Lu, Z.; Picken, S. J.; Yildirim, Z. Oligomeric Rod-Disc Nematic Liquid Crystals. Chem. Commun. 2007, 1245-1247. https://doi.org/10.1039/b614922g.

(64) Archer, E.; Hillebrandt, S.; Keum, C.; Murawski, C.; Murawski, J.; Tenopala-Carmona, F.; Gather, M. C. Accurate Efficiency Measurements of Organic Light-Emitting Diodes via AngleResolved Spectroscopy. Adv. Opt. Mater. 2021, 9, 2000838. 
https://doi.org/10.1002/adom.202000838.

(65) Moon, C.-K.; Kim, S.-Y.; Lee, J.-H.; Kim, J.-J. Luminescence from Oriented Emitting Dipoles in a Birefringent Medium. Opt. Express 2015, 23 (7), A279. https://doi.org/10.1364/oe.23.00a279.

(66) Graf, A.; Liehm, P.; Murawski, C.; Hofmann, S.; Leo, K.; Gather, M. C. Correlating the Transition Dipole Moment Orientation of Phosphorescent Emitter Molecules in OLEDs with Basic Material Properties. J. Mater. Chem. C 2014, 2 (48), 10298-10304. https://doi.org/10.1039/c4tc00997e.

(67) Lee, J. S.; Prabu, A. A.; Kim, K. J. Annealing Effect upon Chain Orientation, Crystalline Morphology, and Polarizability of Ultra-Thin P(VDF-TrFE) Film for Nonvolatile Polymer Memory Device. Polymer (Guildf). 2010, 51 (26), 6319-6333.

https://doi.org/10.1016/j.polymer.2010.10.053. 

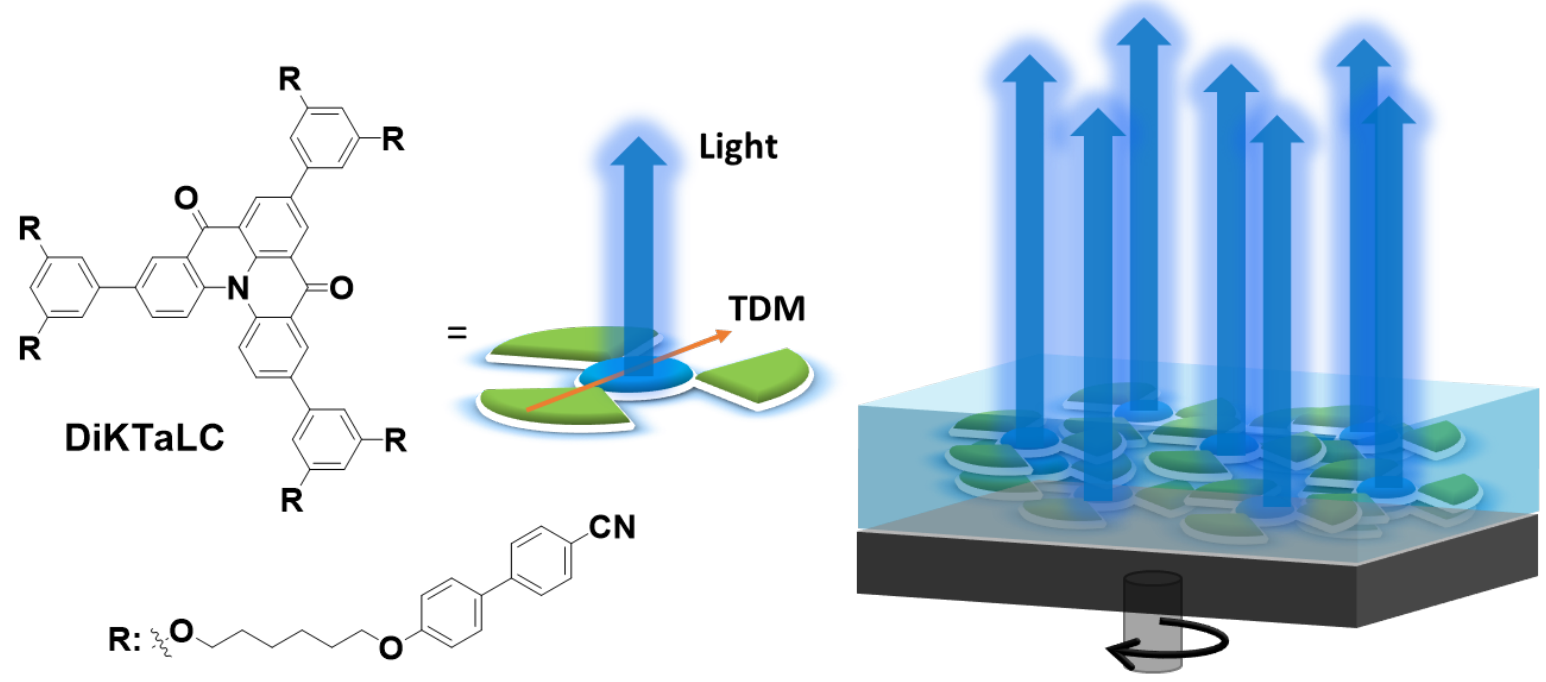